\title{
A Suggestion for Language Teaching by Using Intertitles in Frasier
}

\author{
Sunmee Chang ${ }^{1}$, Manjin Kang ${ }^{2}$ \\ ${ }^{I}$ Professor, Department of English Language and Literature, Hoseo University, South Korea, \\ schang@hoseo.edu \\ ${ }^{2}$ Professor, Department of Korean Language and Culture, Hoseo University, South Korea, \\ kmj@hoseo.edu
}

Corresponding author: Manjin Kang

\begin{abstract}
This study aims to suggest how audiovisual material can be effectively and uniquely used to teach adult learners, especially in advanced or higher levels. Selected for this research is Frasier, a popular American TV comedy/drama series, which is well-written and abundant with linguistic and cultural content. Frasier offers unique differences apart from other general audiovisual materials from TV shows within the same genre. The most prominent and distinguishing feature of Frasier is using 'intertitles.' In silent films, intertitles were inserted intermittently between sequence frames of films to provide an important supplementary component to inform viewers of plot development. They functioned as a conveyance of dialogue and provided related descriptive and narrative material at various points throughout the film. However, the role of intertitles in telling a story in silent films was performed quite differently than in Frasier. This study examines intertitles academically as they were used in the series Frasier and promotes the possibility of utilizing them as a channel for English learning. A brief categorizing analysis of intertitles in Frasier was done by using 264 episodes scripts. The results show that intertitles in Frasier are used to foreshadow the upcoming scenes in each episode. As a suggestion for implementing the uniqueness of intertitles in a practical way, a simple class model/lesson plan is demonstrated to examine the plausibility of applying intertitles for English teaching and learning. Frasier is so comprehensive in its range of linguistically and culturally rich contents that more examinations from applied linguistics or sociolinguistics is expected for future research.
\end{abstract}

Keywords: Audiovisual Material, Intertitles, English Teaching, Class Model

\section{Introduction}

There has been an ever-increasing tendency to use a variety of audiovisual materials from cultural contexts as resources of language input for language learners. This kind of authentic input is regarded as an effective tool in facilitating learning of second or foreign language learners[1]. Through these materials, learners learn their target language, thus "functioning on more profound and integral levels in another culture"'[2]. Even though the authentic language input extracted from these resources was not originally designed nor intended for learning, it conveys an authentic language engagement produced by real speakers or writers for a real audience[3] and is expressed in a variety of formats encompassing news programs, movies, songs, soap operas, comedies, recorded conversations, social meetings, and newspapers.

Received: September 9, 2021; $1^{\text {st }}$ Review Result: October 23, 2021; $2^{\text {nd }}$ Review Result: December 15, 2021 Accepted: January 29, 2022 
Such audiovisual materials have cross-linguistic and cross-cultural values. They contain ideas and opinions in various forms of art and popular culture which are expressed both explicitly and implicitly [4]. This diversity of expression enables them to be a useful platform from which language learners can be immersed in the culture or way of life of the target community. Through a saturation type of exposure to cultural/sociolinguistic issues, learners experience a broadening of their geographical knowledge while finding themselves engaged in many other issues, such as history, politics, and social agendas of the country where the target lanwhaguage is spoken[5]. When a teacher selects appropriate materials, either in their entirety or in segments, which are purposeful and customized for students' needs and levels, this authentic language input provides learners with enhanced opportunities to enjoy a deeper engagement within the acquisition of their target language.

However, the persistent obstacle for educators is 'what to teach' and 'how to teach' with these materials. Despite its popularity, it remains true that most teachers are uncomfortable with using audiovisual materials, and this discomfort is exacerbated due to lack of any standardized direction. The answer to 'what to teach' and 'how to teach' comes with repeated successive trial-and-error attempts and experiences[6]. 'How to teach' may vary depending upon whom the teacher is but recognizing 'what to teach' in the selection process of materials depends on the characteristics and content of the materials themselves[7]. 'What to teach' can be decided according to the level of the learners and the linguistic and cultural contents[7].

This paper is not intended to provide any criteria to choose 'what to teach' or 'how to teach'. Rather, it is aimed to show an example of language teaching through the unique features of a situation comedy (sitcom), which can facilitate other successive attempts and experience for language teachers. Intertitles are not found often in drama or movies these days. Therefore, not much attention has been paid to them, not to mention in research studies. This explains why several of studies quoted as parts of the literature review in this section are from studies done decades ago. Moreover, most of these studies were not about the content of the intertitles themselves but about their use, especially as educational materials. The significance of this study lies in this regard. This study shows that intertitles, which are not often focused upon for content but look intriguing in audiovisual materials, can be used as a unique tool to facilitate language teaching and learning. 'How can intertitles be used for language teaching?' could be the research question for this study. The target learners are adults with advanced levels of cultural knowledge about the chosen language, which is English. This study intends to provide a model of teaching a language through audiovisual materials.

\section{Contents}

\subsection{Frasier, A Selected Sitcom}

Frasier, a hit American comedy series that ran from 1993 to 2004 with over two-hundred-and-sixty episodes, centers around a radio talk show host named Frasier and involves his family and friends in Seattle, Washington. Audiovisual materials from this show seem to be quite suitable material for language teaching, and several points can be mentioned.

First, it has relatively unique linguistic features of discourse patterns which fit with the level of the learners. Compared with other popular TV comedy shows, the overall linguistic features of Frasier are much more complicated.

Second, each episode of the show has various themes and plots[8] with extraordinarily amusing scenes. In most of the other popular American sitcoms and dramas, characters draw laughter from the audience by usually doing superficial wordplay or forging contrived situations, but in Frasier, most of the laughing points are created as the plot becomes more complex in the context of episodes[7]. This means the deeper one thinks about the situation the greater the humor becomes. 
Third, since there are so many episodes with many situational themes and plot elements, teachers are sure to find an episode which seems appropriate for their intended lessons. The selection process has a straightforward beginning by the choice of an episode based upon its title, which is necessarily brief and yet comprehensive enough to show what the episode is about.

Fourth, the plots, themes, and issues in Frasier, because of their sheer variety and uniqueness, are very attractive to advanced adult learners. As adult learners from beginners to advanced level find vocabulary, grammar and conversation drills tedious, such as a contrived dialogue between customers and waiters at a restaurant. Obviously adult learners at advanced levels need and want to study English in different ways that offer authenticity, humor, and interaction with an English-speaking culture.

Fifth, together with linguistic components, adult learners gain comprehensive understanding about interesting psychological aspects that are formed by cultural expectations. This understanding is of the complicated relationships between men and women, of the lifestyles of the affluent, and of the political and social issues experienced through conversations of characters in the show.

Sixth, from a most important practical level, unlike other similar sitcoms, dramas, and comedy shows, what is truly unique about Frasier is that each episode is divided into several chapters and preceding each one is an intertitle that says what the upcoming scene is about. The intertitles are presented in various forms and foreshadows upcoming scenes directly or indirectly.

Because Frasier offers a plethora of learning opportunities which require a greater study than the scope of this paper, the focus here is devoted exclusively to the unique feature of intertitles as a focused channel for learning. The feature of intertitles is prominently dominant all over the episodes. It foreshadows what will happen in the plot's scenes in various ways. The uniqueness of this use of intertitles in the series is very intriguing in language learning, making curiosity an important motivator in language acquisition.

\subsection{Intertitles}

\subsubsection{Categories and Functions}

The term 'intertitles' has an uncertain etymology with an existence traceable back as early as 1910[9]. Intertitles are printed texts positioned amid the scenes of a film or a drama at various points, which were usually used with silent films to show dialogues from the preceded scenes or to provide explanations of the scenes[10]. In modern films and dramas intertitles are still used to supplement, or to distinguish various acts of a film. However, they are most used as part of epilogues of historical dramas, or of films based on true events, to properly explain what happened to the depicted characters and events upon the conclusion of the stories[10].

Considering that intertitles are used to convey character dialogue, or descriptive narrative material related to the upcoming scenes, a scholar distinguishes these two major categories: dialogue intertitles and expository intertitles, which are used to address the audience directly[11]. Dialogue intertitles, known as spoken titles, represent the characters' speech, while expository intertitles, also called explanatory and narrative intertitles, explain some aspect of the film's action[12].

Many scholars have explored the variety of functions of intertitles other than just the above two functions[10][13]. This means that the categories and functions of intertitles are expansive rather than definite and exclusive. While the explanation focusing on the two functions of categories gives us a general understanding of intertitle operation, more categories and their functions of intertitles can be added[11]. 


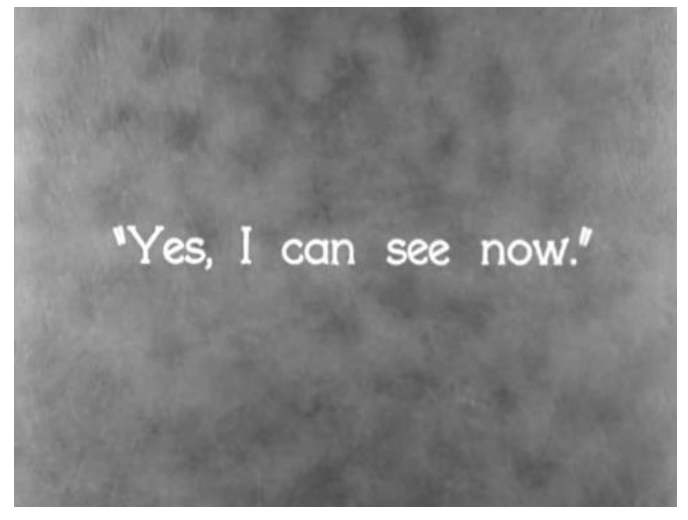

[Fig. 1] Dialogue Intertitles From City Lights (1931)

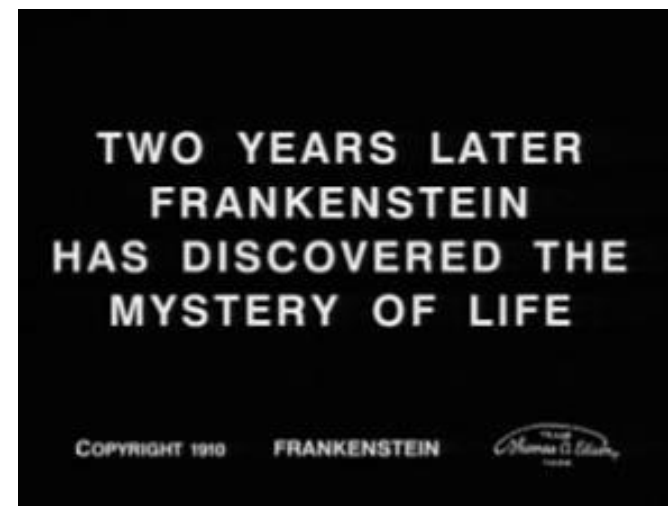

[Fig. 2] Expository Intertitles

From Frankenstein (1931)

\subsubsection{Intertitles in Frasier: Methods}

The most prominent feature of Frasier, distinguishing it from other TV shows, is the use of intertitles. As discussed above, intertitles had usually been used in silent films. However, the use of intertitles found in Frasier is unique because the texts of intertitles foreshadow the scenes that follow in various ways. The uniqueness of these types of intertitles in the series is intriguing to the viewer and piques their curiosity to see more. Frasier intertitles show captivating forms not found in other movies or dramas where intertitles were used. They fundamentally play their traditional expository roles before the scenes, but their creative use of language to describe the scenes are various.

To see how intertitles play their role in Frasier in detail, they are categorized under descriptive headings. Total 264 episode scripts were looked and total 835 intertitles are classified in three ways depending upon their many details(Table 1). Some examples are quotes from classic literature, parodies of famous lines or song titles, and satire in describing the situations of the scenes. Each of the intertitles has its own quality and characteristics. Noticeably, all of them look very familiar and use idiomatic or conventional expressions.

[Table 1] Intertitles Classification of Frasier[1]

\begin{tabular}{|l|l|}
\hline Classification & Details \\
\hline \multirow{4}{*}{ Forms } & Characters (celebrities, movies, fairy tales...) \\
\cline { 2 - 2 } & Titles (movies, play, show, book, song, etc.) \\
\cline { 2 - 2 } & Famous Quotes \\
\cline { 2 - 2 } & Idiomatic or conventional expressions \\
\hline \multirow{4}{*}{ Manners } & Parody \\
\cline { 2 - 2 } & Word play \\
\cline { 2 - 2 } & Direct description \\
\hline Range & Part \\
\cline { 2 - 2 } & Whole \\
\hline
\end{tabular}

[Table 2] Example Intertitles in Frasier

\begin{tabular}{|l|l|l|l|l|}
\hline$\#$ & Season & Episode/ Title & Intertitles & Detailed Classification \\
\hline 1 & 1 & 14/ Can't Buy Me Love & Driving Miss Daphne & Movie title \\
\hline 2 & 8 & 16/ DocuDrama & Seattle, we have a problem. & Famous quote \\
\hline 3 & 2 & 2/ The Unkindest Cut of All & The unkindest cut of all & Lines from a play \\
\hline 4 & 2 & 12/ Roz in The Doghouse & $\begin{array}{l}\text { You can't teach an old bulldog new } \\
\text { tricks. }\end{array}$ & Direct description \\
\hline 5 & 8 & 21/Semi-Decent Proposal & Tuesdays with Frasier & Book title \\
\hline 6 & 11 & 7/ Maris Returns & Don't cry for me Argentina. & Song title \\
\hline
\end{tabular}




\begin{tabular}{|l|l|l|l|l|}
\hline 7 & 10 & $5 /$ Tales from The Crypt & $\begin{array}{l}\text { No Zombies were harmed in the } \\
\text { filming of this episode }\end{array}$ & Conventional expression \\
\hline 8 & 4 & $\begin{array}{l}8 / \text { Our Father Whose Art Ain't } \\
\text { Heaven }\end{array}$ & Our father whose art ain't heaven & \\
\hline
\end{tabular}

As seen above, the many interesting examples of intertitles in Frasier serve to keep the viewer curious and focused on the developing plot. "Driving Miss Daphne" (\#1) is a parodied phrase taken from a movie title to foreshadow an upcoming - scene. This intertitle depicts the scene where Daphne, one of main characters, is having a driving date with a man, which didn't work out well. It is borrowed from the title of a movie, Driving Miss Daisy[7].

"Houston, we have a problem" is a popular quote from a phrase believed to be uttered by an astronaut during the near catastrophe of the Apollo 13 space mission. Since then, this phrase has been used as an idiomatic expression when people are in trouble. "Seattle, we have a problem" (\#2) foreshadows what will happen in the upcoming scene. As foreshadowed, something about space is talked about. In this scene, the main character, Frasier Crane, a radio talk show host, has a producer named Roz, who has the chance to create her own documentary with the theme of outer space. Frasier wants to contribute, but she dismisses him often and hires a former astronaut, which triggers conflicts between herself and Frasier[14]. Instead of the city of Houston, the city of Seattle, which is the background city of Frasier is used in the phrase.

"The unkindest cut of all" (\#3) is a famous line from Julius Caesar, Shakespeare's play, which originally refers to the emotional pain of betrayal Caesar felt when Brutus slashed Caesar with a knife. But in the intertitle "unkindest cut" is used to describe the scene that follows very differently. When Eddie, the dog that belongs to Frasier's father, Martin, fathered a litter of puppies of a neighbor's dog, Frasier was angry with Martin, who should have neutered Eddie. Ultimately, Eddie got "the unkindest cut" after all.

When one of Frasier's colleagues, whose nickname is "Bulldog", has a chance to work with Roz to produce his show, who is Frasier's producer, it doesn't work well as Bulldog refuses to adapt to working with a woman. Using the common English idiom of 'you can't teach an old dog new tricks' the intertitle has "You can't teach an old bulldog new tricks"(\#4) and seems to describe the situation accurately by substituting "dog" with "bulldog."

The next example is the episode where the intertitle (\#5) describes another Frasier's attempt to gain access to an attractive woman, Lana who he dated briefly in the past [15]. In the scene after the intertitle, he makes a deal with Lana on tutoring her son in history on Tuesdays[15]. While the intertitle itself has little to do with the main theme of the episode, it describes the scene of Frasier's romantic attempt in an amusing way.

While intertitle (\#6) doesn't seem to parody what happens in the scene that follows, it does show that Niles, Frasier's brother, has an ex-wife who was killed and was from Argentina. It is just a cue that the intertitle has been taken from this song title.

\subsubsection{The Usefulness of the Intertitles in Frasier}

Frasier is itself a very useful and appropriate teaching material reservoir to develop language learners' language skills and stimulate intellectual curiosity about concepts that transcend language[7]. What makes Frasier an even more exceptional material is its interesting pattern of discourse through intertitles. Traditional forms of intertitles are effective devices for teaching a language since they exactly show dialog and give background knowledge of scenes in a written form. Learners can still comprehend language by reading when spoken language eludes them. However, the intertitles of Frasier stimulate and make learners think more deeply to understand both their literal meaning and underlying metaphorical meaning. For example, when an intertitle that read "no Zombies were harmed in the 
filming of this episode" (\#7) is taught, its literal meaning is not the only focus, but its parodic nature is of open for discussion for more complete understanding. Since its origin is found among ending credits of movies that involve animals, learners may learn the fact that "no animals were harmed in the filming this movie" is one of conventional lines of a movie's ending credits.

"Our father whose art ain't heaven" (\#8) is a comic parody of a phrase in the Lord's Prayer for describing Frasier's artistically inept father. Learners are exposed to learn a non-standard but interesting grammar point, and they may also realize how strongly Christianity is embedded in Western languages and cultures, as Buddhism and Confucianism are deeply related to Asian languages and cultures[6].

Because of its relative complexity and the nature of its contents, adult learners at advanced or higher levels have much to learn through the intertitles of Frasier. To maximize comprehension, learners need to have a certain level of cognitive capacity and background knowledge. The teacher is also a critical element for the successful use of intertitles as teaching materials. Those who intend to teach by using the intertitles of Frasier should be equipped with more knowledge than that of just language. They need to be aware of the background nature of the intertitles and a wide variety of related subjects which interconnect with the ideas the intertitles reference, such as literature, films, songs, and cultural background information.

While the intertitles are just one component of teaching material from Frasier, they are in and of themselves clear enough in the gist they provide for each upcoming scene to be used individually as excellent language teaching aids. They make this comedy series unique in the opportunity to provide useful materials for teaching English. Above all, they make it rather differentiated from others. Learners can experience something beyond conventional methods of learning a language that usually comes through more generalized audiovisual materials[16]. Frasier intertitles foster more brainstorming, expand the imagination, and intuitively infer both the surface and the underlying meaning of English as they improve English proficiency.

\subsubsection{Sample Lesson Plan}

Here is a general example of lesson plan in using Frasier. This example lesson plan is aimed to cultivate and facilitate communicative language teaching (CLT) and learning in a language classroom where the teacher and the students construct the contents of learning through dynamic interactions. In the CLT classroom, various activities may be adopted, such as role-play, group work, information gap, opinion sharing, and many other interactive activities. The sample lesson plan suggested in this section has been designed based on the theoretical and practical approach of CLT.

[Table 2] Example Lesson Plan Using Frasier

\begin{tabular}{|c|c|}
\hline Students' Level & Advanced Adults \\
\hline Preparation & Students watch the episode the teacher assigned beforehand as homework \\
\hline $\begin{array}{l}\text { Comprehension } \\
\text { Check }\end{array}$ & $\begin{array}{l}\text { 1. Let the students describe and talk about the general impressions they get from } \\
\text { the episode. } \\
\text { 2. Let each student have a chance to express their feelings about the episode. If the } \\
\text { class size is too large this can be done by group. }\end{array}$ \\
\hline Further Check & $\begin{array}{l}\text { 3. Have each student or each group report their answers. } \\
\text { 4. Distribute a script and go over it scene by scene with video. } \\
\text { 5. Ask the students any questions about each scene to check their comprehension. }\end{array}$ \\
\hline $\begin{array}{l}\text { Student Group } \\
\text { Tasks }\end{array}$ & $\begin{array}{l}\text { 6. After reviewing each scene, the students now have enough knowledge of the episode. } \\
\text { Have them do group work again with several tasks. } \\
\text { A. What are the characteristics of each character? Which line signifies each } \\
\text { character's characteristics? }\end{array}$ \\
\hline
\end{tabular}




\begin{tabular}{|c|c|}
\hline & $\begin{array}{l}\text { B. What are the dynamics among characters in the episodes, depending on their } \\
\text { themes? } \\
\text { C. What is the total number of intertitles in this episode? What are their meanings } \\
\text { and roles? Are they related to the scenes coming after them? Then, how? } \\
\text { D. Are there any interesting expressions or something you don't understand? }\end{array}$ \\
\hline Group Reports & Call for a reporting session and let the groups share what they have found and discussed. \\
\hline $\begin{array}{l}\text { Group Reports } \\
\text { with Possible } \\
\text { Answers }\end{array}$ & 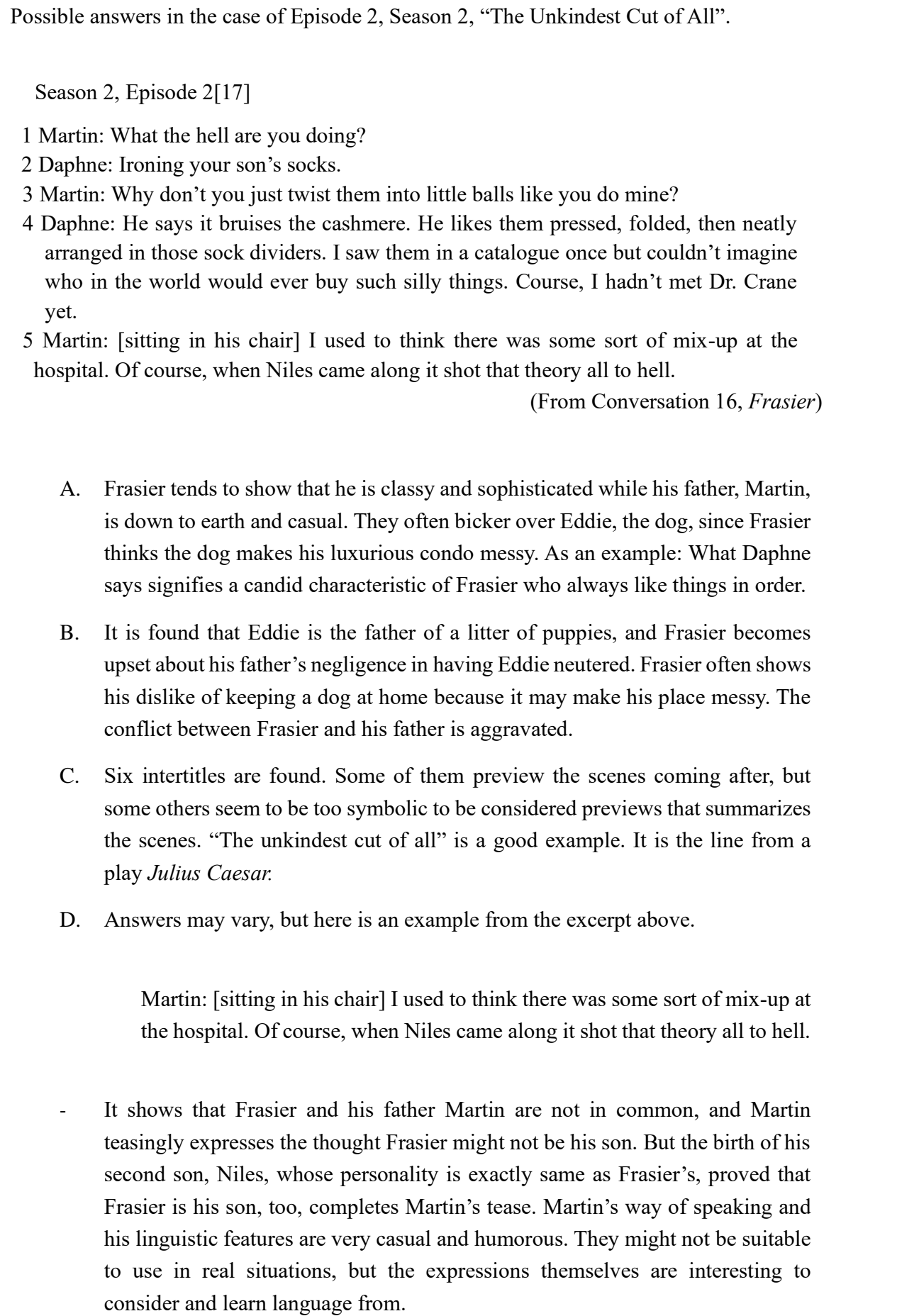 \\
\hline $\begin{array}{l}\text { Expected Students } \\
\text { Participation }\end{array}$ & $\begin{array}{l}\text { 8. Since the students are advanced adults, they are capable of satisfactory answers and } \\
\text { discussion results. The whole class helps and corrects language use of individuals or } \\
\text { groups as task results are presented to the class. }\end{array}$ \\
\hline
\end{tabular}




\begin{tabular}{|c|c|}
\hline $\begin{array}{l}\text { Teacher's } \\
\text { Management }\end{array}$ & $\begin{array}{l}\text { 9. The teacher may point out more lines that signify lesson goals as Frasier's } \\
\text { characters interact and clarify any confusing terms among the students regarding } \\
\text { intertitles. New or difficult linguistic features are to be checked as well. } \\
\text { Additionally, the extensions of the humor of neutering Eddie to Martin's loss of } \\
\text { vitality as an aging man. }\end{array}$ \\
\hline Things to Consider & $\begin{array}{l}\text { 10. Since teaching with a single episode is time consuming, the judicial selection of } \\
\text { lines for learning expressions and grammar is essential. Along with this, some } \\
\text { interesting cultural elements and contextual knowledge is to be considered for } \\
\text { more in-depth teaching. }\end{array}$ \\
\hline Wrapping-up & $\begin{array}{l}\text { 11. As a wrap-up, give the students follow-up assignments for the next class as } \\
\text { homework. For example: Use video clips available on YouTube and do the } \\
\text { following: } \\
\text { A. Pick one scene from the episode where characters are thought to have the most } \\
\text { interesting conversation. } \\
\text { B. From the scene picked, make a list of interesting expressions. Those expressions } \\
\text { may have sarcasm, double meanings, colloquialisms, or sexual connotations. } \\
\text { C. Make a list of difficult new vocabulary and structures. } \\
\text { D. Use captions if available, otherwise use a script found online if listening } \\
\text { comprehension is too difficult. } \\
\text { Note: The most effective learning comes from concentrating on conversations and } \\
\text { doing homework precisely. }\end{array}$ \\
\hline & ** The next lesson is determined by the completion level of students' homework. \\
\hline
\end{tabular}

\section{Conclusion}

Due to rapid technological developments, access to a wide range of audiovisual materials is increasingly becoming readily available for teachers worldwide. Many researchers have underscored the pedagogical values of audiovisual materials as they are incorporated into language acquisition and culture knowledge. Just as with films and dramas, the sitcom Frasier seems to be an efficient and appropriate teaching device to develop language learners' language skills and stimulate intellectual curiosity about culture that extends beyond language itself. The use of intertitles in Frasier has the undeniable capacity to arouse the learners' motivation and inspire their potential to engage with their own inner responses to learning. The linguistic features and cultural lessons to be learned from Frasier extend far beyond the rote learning methods of language represented by the rudimentary dialogs of 'where are you going?' or 'how old are you?' As learners feel the attraction of being engaged in the characters of Frasier through the lure of intertitles, it is expected that learners become more engrossed in the series character development, discourse, plots, and themes, and they are more inclined to reach their own goals of learning and acquiring both linguistic and cultural knowledge. Because of this very experience of learning through Frasier, when it comes to applied linguistic content, learners at advanced or higher levels are especially receptive, but the themes and plots are not appropriate for learners under the age nineteen years old. Learners at relatively higher levels are likely more capable to understand and enjoy Frasier's uniqueness through intertitles. Because the sitcom ended in the year of 2004, ample time 
has passed that has allowed for scripts and video clips to be easily found online, meaning that both the teacher and learners can easily access the educational material that Frasier has to offer.

The exploration in this paper focusing on using intertitles from Frasier to teach language acquisition touches just the tip of the iceberg of the abundant lesson opportunities Frasier provides. But in this focus, it has shed even more light on what other researchers continue to investigate concerning the pedagogical value of utilizing audiovisual materials as the source of authentic linguistic and cultural input for language learners. The question of how to teach, or how to apply practical applications, is in part determined independently by the teacher's comfort level and skill set, but what is a prediction for future studies to observe is that Frasier and its intertitles are in rare use as teaching material in spite of its unique qualities. This paper views that the use of the unique feature of intertitles found in Frasier can be highly beneficial to advanced adult learners in mastering English language. It is certainly necessary to verify and measure how using intertitles for language teaching is useful and beneficial. Future empirical research with a selected group of learners is expected to compensate for this limitation.

Without exaggeration, virtually, every line, scene and episode of Frasier is worthy of being studied with its intertitles providing a framework for such study. As such, more research studies from a perspective of sociolinguistics or applied linguistics are highly feasible.

\section{References}

[1] T. Chao, A diary study of university EFL learners' intercultural learning through foreign film, Language, Culture and Curriculum, (2013), Vol.26, No.3, pp.247-265, DOI: 10.1080/07908318.2013.833936

[2] J. L. Stephens, Teaching culture and improving language skills through a cinematic lens: A course on Spanish film in the undergraduate Spanish curriculum, ADFL Bulletin, (2001), Vol.33, No.1, pp.22-25.

[3] A. Gilmore, Authentic materials and authenticity in foreign language learning, Language Teaching, (2007), Vol.40, No.2, pp.97-118, DOI: https://doi.org/10.1017/S0261444807004144

[4] Y. Suh, Y. Jung, Raising critical awareness of watching American TV cartoons in an ESL context, English Language \& Literature Teaching, (2012), Vol.18, No.3, pp.223-242, UCI: G704-000960.2012.18.3.001

[5] T. Bahrani, R. Soltani, An overview on how to utilize authentic language input for language teaching, Language in India, (2012), Vol.12, No.2, pp.800-807.

[6] S. Chang, Developing a task-based English lesson through a movie, English Language \& Literature Teaching, (2014), Vol.20, No.4, pp.1-22, UCI: G704-000960.2014.20.4.005

[7] S. Chang, Using a popular TV comedy series in teaching English: Focusing on Frasier, Journal of English Teaching through Movies and Media, (2015), Vol.16, No.4, pp.25-49, DOI: 10.16875/stem.2015.16.4.25

[8] J. Graham, Frasier, Pocket Book, pp. 1-276, (1996)

[9] A. Gaudreault, T. Barnard, Titles, subtitles, and intertitles: Factors of autonomy, factors of concatenation, Film History: An International Journal, (2013), Vol.25, No.1-2, pp.81-94, DOI: 10.2979/filmhistory.25.1-2.81

[10] S. Berry, Rethinking Intertitles: The Voice and Temporality of Lyric Intertitles in The Cry of the Children, LiteratureFilm Quarterly, (2014), Vol.42, No.4, pp.594-608.

[11] B. Chisholm, Reading Intertitles, Journal of Popular Film and Television, (1987), Vol.15, No.3, pp.137-142, DOI: https://doi.org/10.1080/01956051.1987.9944095

[12] B. Salt, Film Style and Technology: History and Analysis, Starword, pp.1-453, (2009)

[13] W. F. Van Wert, Intertitles, Sight and Sound, (1980), Vol.49, No.2, pp.98-105.

[14] D. Lee (Director), DocuDrama [Television series episode], In P. Casey (Producer), Frasier. New York: National Broadcasting, (2001a) 
[15] D. Lee (Director), Semi-Decent Proposal [Television series episode], In P. Casey (Producer), Frasier. New York: National Broadcasting, (2001b)

[16] K. S. Song, Implicature in English Computer-Mediated Discourse: Linguistic Devices, The Journal of Studies in Language, (2009), Vol.24, No.4, pp.755-777, DOI: 10.18627/jslg.24.4.200902.755

[17] D. Hackel (Director), The unkindest cut of all [Television series episode], In P. Casey (Producer), Frasier. New York: National Broadcasting, (1994) 